www.jmscr.igmpublication.org

Impact Factor 5.84

Index Copernicus Value: 83.27

ISSN (e)-2347-176x ISSN (p) 2455-0450

crossref DOI: _https://dx.doi.org/10.18535/jmscr/v5i5.192

\title{
Study of clinical profile of Guillain Barre Syndrome
}

\author{
Authors \\ Priti Dave $^{1}$, A.G. Diwan ${ }^{2}$, Baldeep Singh ${ }^{3}$, Saurabh Thavare ${ }^{4}$, Kunal Bonde ${ }^{5}$, \\ Bhargav Desai ${ }^{6}$ \\ ${ }^{1}$ Professor, Dept of Medicine, BVDUMC, Pune \\ ${ }^{2}$ HOD, Dept of Medicine, BVDUMC, Pune \\ ${ }^{3,4,5,6}$ Postgraduate Student, BVDUMC, Pune \\ Corresponding Author \\ Priti Dave \\ Professor of Medicine, Bharati Vidyapeeth University Medical College, Pune \\ Email-dave.priti7@gmail.com, Pin- 411045.Ph No-9822790490
}

\begin{abstract}
Guillain Barre Syndrome (GBS) is an acute fulminant, inflammatory polyradiculoneuropathy. We studied clinical features, antecedent events, diagnostic features, incidence of respiratory paralysis and corelation of treatment modality and outcome in 30 patients of GBS admitted in a tertiary hospital. We found tht 50\% of patients had evidence of preceedings illness. The common clinical features observed where paraparesis $(63.33 \%)$ and quadriparesis $(36.67 \%)$ of patients. Incidence of respiratory paralysis was observed to be $13.33 \%$. There was a direct corelation between presence of bulbar palsy and respiratory failure in our study. We also found no difference in treatment modality and outcome of patient disease between plasmapharesis and intravenous immunoglobulin.

Keywords: Guillain Barre Syndrome, Polyradiculoneuropathy, Respiratory Paralysis.
\end{abstract}

\section{Introduction}

Guillain-Barré syndrome (GBS) is an acute, fulminant, autoimmune, inflammatory polyradiculoneuropathy with incompletely understood etiology. ${ }^{1,2}$ It is also known as Landry's Paralysis ${ }^{3}$. Global annual incidence is reported to be $0.6-2.4$ cases per 100,000 per year. Men are 1.5 times more commonly affected than women .It presents as progressive, flaccid, symmetrical muscle weakness with reduced or absent reflexes. It is having a variable presentation from mild disease to involvement of all four limbs with respiratory muscles paralysis, cranial nerves and even autonomic nervous system affection.
Diagnosis of GBS is mostly clinical. CSF examination shows albumin cytological dissociation at the end of first week.NCV studies if available is of use ${ }^{4}$.

Aim

- To determine the clinical profile of Guillain Barre syndrome in a tertiary centre.

\section{Objectives}

1. To assess the incidence of respiratory failure and need of artificial ventilation. 
2. To correlate certain clinical presentations with outcome of the patient at discharge.

3. To correlate the outcome with treatment modality.

\section{Material and Method}

We studied 30 patients suffering from GBS aged 18-80 years admitted in a tertiary Hospital. GBS was diagnosed by modified Asbury criteria. A detailed history with particular attention to the date of onset and tempo of the neurological disability, time taken to reach clinical peak, presence of dyasthesias, muscle pain and autonomic symptoms was noted. Any history of any preceding event within a period of one month prior to onset of symptoms was noted. A detailed clinical examination was done at the time of admission, at the time of clinical peak and at the time of discharge. Special attention was given to cranial nerves involvement, improvement or worsening of power, condition of reflexes, bladder involvement, sensory involvement and any ataxia present. Bedside autonomic function tests like resting heart rate, resting blood pressure, measurement of postural hypotension were performed at the time of admission and discharge. Investigations like complete blood count (CBC), urine examination, ESR, blood sugar levels, serum electrolytes, renal function test, HIV, HBsAg were done in all patients. Cerebrospinal fluid examination was done at the end of first week.All the patients were subjected to nerve conduction velocity. Treatment of patients suffering from GBS included intravenous immunoglobulin (IVIG) or plasmapheresis. Outcome of patients was observed at the time of discharge and any corelation of outcome with clinical presentation if present was noted. Improvement at the time of discharge was defined as improvement in power of quadriparesis or paraparesis, or/and improvement in return of reflexes, or/ and improvement in cranial nerve palsies as compared to signs and symptoms at the peak time of the disease.

\section{Observations and Results}

The mean observed age of GBS patients was $37.07 \pm 15.98$ years and the male to female ratio was 1.31:1. Antecedent events were seen in 50\% of patients ,of which $20 \%$ had gastroenteritis , $16.66 \%$ had respiratory tract infection(RTI), $13.33 \%$ had preceding acute febrile illness excluding RTI and gastroenteritis, out of which 1 patient was diagnosed to be suffering from dengue fever and 1 was HIV positive. The duration between preceding illness and onset of GBS in majority of patients was within 1 week (46.67\%) followed by between 1-2 and 2-3 weeks (26.66\% each).The most common clinical feature observed in our study was paraparesis in $63.33 \%$ patients and quadriparesis in $36.67 \%$ patients. (Table 1)

Out of $33.33 \%$ patients who manifested with autonomic disturbances major manifestations were tachycardia $(20 \%$ patients) followed by bradycardia and postural hypotension.$(6.66 \%$ patients each).The commonest cranial nerve involved was facial nerve in $26.67 \%$ and was bilateral in nature. Glossopharyngeal and vagus nerves were involved in $13.33 \%$ patients. Out of 30 patients, $13.33 \%$ had respiratory paralysis during the course of illness. Out of 4 patients 2 $(50 \%)$ required respiratory support within one week of onset of weakness. Mean time was 4th day of weakness while $2(50 \%)$ patients required ventilator support within 1-2 weeks of onset of weakness. (Table3).In our study out of 30 patients,4(13.33\%) patients had respiratory paralysis and similar no. of patients $13.33 \%$ had bulbar palsy. However out of 4 patients with respiratory paralysis, $3(75 \%)$ patients had bulbar palsy also. (*1 patient which manifested with respiratory paralysis and bulbar palsy, died). (Table 4).

It was observed that nerve conduction studies were abnormal in all 40 patients (100\%). 90\% patients had absent /delayed f-wave latencies and slowing of conduction velocity, which was the most common abnormality observed. The prolonged distal motor latencies were observed in 
$76.67 \%$ patients while absent/reduced SNAPs was seen in $66.65 \%$ patients. In the present study CSF examination showed albumino-cytological dissociation in $96.66 \%$ patients.

Out of 30 patients, $60 \%$ patients reached the plateau phase of disease progression in the $2^{\text {nd }}$ week of illness. Meanwhile 20\% patients plateaued early, within the first week whereas $13.33 \%$ and $6.67 \%$ patients manifested with a delayed plateau phase $\left(3^{\text {rd }}\right.$ and $4^{\text {th }}$ week respectively). Out of 30 patients, $76.67 \%$ patients received IVIG line of treatment while $23.33 \%$ patients received plasmapheresis.There was no significant statistical correlation between any one mode of treatment in relation to outcome. $(\mathrm{P}>0.050)$

Table 1: Distribution according to clinical features

\begin{tabular}{|l|l|l|l|}
\hline Clinical features & $\begin{array}{l}\text { Male } \\
(\mathbf{n = 1 7}) \\
(\%)\end{array}$ & $\begin{array}{l}\text { Female } \\
(\mathbf{n = 1 3 )} \\
(\boldsymbol{\%})\end{array}$ & $\begin{array}{l}\text { Total } \\
(\mathbf{n = 3 0}) \\
(\%)\end{array}$ \\
\hline Quadriparesis & $06(35.29)$ & $05(38.46)$ & $11(36.67)$ \\
\hline Paraparesis & $11(64.71)$ & $08(61.53)$ & $19(63.33)$ \\
\hline Cranial Involvement & $08(47.06)$ & $04(30.76)$ & $12(40.00)$ \\
\hline Bladder Involvement & $02(11.76)$ & $0(00)$ & $02(6.67)$ \\
\hline Sensory Symptom & $13(76.47)$ & $06(46.15)$ & $19(63.33)$ \\
\hline $\begin{array}{l}\text { Atypical presentation } \\
\text { (Descending Paralysis) }\end{array}$ & $00(00)$ & $0(00)$ & $00(00)$ \\
\hline Respiratory Paralysis & $03(17.65)$ & $1(07.69)$ & $04(13.33)$ \\
\hline Autonomic dysfunction & $06(35.29)$ & $4(30.76)$ & $10(33.33)$ \\
\hline Cerebellar signs & $0(00)$ & $0(00)$ & $00(00)$ \\
\hline Muscle Pain & $01(05.88)$ & $02(15.38)$ & $03(10.00)$ \\
\hline
\end{tabular}

(Multiple response Present)

Table 2: Distribution according to various signs encountered in patients

\begin{tabular}{|l|l|l|l|}
\hline Signs & $\begin{array}{l}\text { Male (n=17) } \\
(\boldsymbol{\%})\end{array}$ & $\begin{array}{l}\text { Female } \\
(\mathbf{n = 1 3}) \mathbf{( \% )}\end{array}$ & $\begin{array}{l}\text { Total } \\
(\mathbf{n = 3 0})(\%)\end{array}$ \\
\hline Areflexia & $17(100)$ & $13(100)$ & $30(100 \%)$ \\
\hline Sensory abnormalities & $01(05.88)$ & $01(07.69)$ & $02(6.66 \%)$ \\
\hline Sphincter disturbances & $01(05.88)$ & $01(07.69)$ & $02(6.66 \%)$ \\
\hline Wasting (distal muscle) & $03(17.65)$ & $01(07.69)$ & $04(13.33 \%)$ \\
\hline
\end{tabular}

Table 3: Distribution as per progression to respiratory paralysis during illness

\begin{tabular}{|l|c|c|}
\hline Duration & No. of Patients $(\mathbf{n}=4)$ & Percentage \\
\hline$<1$ week & 02 & 50.00 \\
\hline $1-2$ weeks & 02 & 50.00 \\
\hline$>2$ weeks & 00 & 00 \\
\hline
\end{tabular}

Table 4: Co-relation of Bulbar palsy with respiratory failure and outcome

\begin{tabular}{|l|l|l|l|}
\hline $\begin{array}{l}\text { Respiratory } \\
\text { Paralysis }\end{array}$ & $\begin{array}{l}\text { Bulbar palsy } \\
\text { (Absent) }(\boldsymbol{\%})\end{array}$ & $\begin{array}{l}\text { Bulbar palsy } \\
\text { (Present) } \\
(\boldsymbol{\%})\end{array}$ & $\begin{array}{l}\text { Total } \\
(\mathbf{n = 3 0}) \\
(\boldsymbol{\%})\end{array}$ \\
\hline Absent & $25(83.33)$ & $01(03.33)$ & $26(86.67)$ \\
\hline Present & $01(03.33)$ & $03 *(10.00)$ & $04(13.33)$ \\
\hline
\end{tabular}

$(\mathrm{X} 2=9.60 ; \mathrm{df}=1 ; \mathrm{P}=0.002 ; \mathrm{P}<0.05$ Statistically significant $)$

\section{Discussion}

In the present study, it was observed that majority of patients were in the age group 20-40 years $(60 \%)$. GBS occurs in all age groups and the incidence varies. Peaks are noted in late adolescence, young adulthood, elderly and in females after pregnancy. The first peak likely correlates with increased risk of cytomegalovirus and campylobacter jejuni infection and in elderly the second peak may be due to failing immune suppressor mechanism ${ }^{5}$. Our study did not show peak in elderly, We found male preponderance (M:F,1.31:1) in our study like that of a study by Sharma $\mathrm{G}^{6}$ who found the ratio to be $1.82: 1$.

In the present study, it was observed that $50 \%$ patients had preceding illness. Majority of the patients i.e $20 \%$ had gastroenteritis while respiratory tract infection (RTI) was present in $16.66 \%$ patients. A study quoted that GBS is preceeded by antecedent events in two third of cases. Respiratory tract infection and gastroenteritis were seen in $40 \%$ and $20 \%$ cases in their study ${ }^{7}$. The common organisms isolated were campylobacter jejuni, Cytomegalovirus infection, Ebstein-Barr Virus, and Mycoplasmapn-uemoniae. Haemophlilus influenza, parainfluenza type 1, influenza $A$ and $B$, adenovirus, varicella zoster, and parvovirus B 19 viruses infections were not more common than in controls in their study ${ }^{7}$. DhadkeS $\mathrm{V}$ et al, found the most common preceding illness (11 out of 22 patients) to be upper respiratory infection, next was gastrointestinal infection (10 patients out of 20). ${ }^{1}$

In our study, 1 patient had preceding history of dengue fever (NS1 and IgM both positive), who developed acute onset ascending limb weakness after 4 days of onset of fever and was not 
associated with any plasma leak (in the form of ascites or pleural effusion). There are many case reports which describes that GBS had been preceded by a proven episode of dengue fever $^{8,9,10,11}$. Nonself-antigens (infectious agents, vaccines) misdirect to host nerve tissue like axons and myelin through molecular mimicry mechanism ${ }^{9}$.It appears that Dengue fever as antecedent infection in GBS is little underestimated specially when in India it is a common infection and one should be aware of this complication of dengue.

In the present study 1 patient $(3.33 \%)$ was found to be HIV positive. The patient had preceding illness of diarrhea followed by neurological signs.Brannagan $\mathrm{TH}$ et $\mathrm{al}^{12}$ reviewed medical records of 10 patients with HIV-GBS at five hospitals from 1986 to 1999 and observed neuropathy typically occurs early in HIV infection, even at seroconversion, prior to developing acquired immunodeficiency syndrome (AIDS). The mean CD4 count was $367 / \mathrm{mm}^{3}$ (range 55-800). Our patient had a CD4 count of 520 /cumm. A mild cerebrospinal fluid (CSF) pleocytosis in GBS suggests HIV infection, but is frequently absent. Our HIV positive patient had pleocytosis without albumin- cytological dissociation. As we were not aware of previous HIV status of our patient it is difficult to say whether he was in seroconversion state or it was a mere co-association.

In the present study; the duration between preceding illness and onset of symptoms for most patients i.e. 11 out of $15(73.29 \%)$ was observed to be within 2 weeks of antecedent event, while remaining $4(26.67 \%)$ patient developed GBS between 2-3 weeks following the preceding illness. Shubhangi Vithal Dhadke et al1 ${ }^{1}$, showed majority i.e. 20 out of 22 patients developed neurological illness within 4 weeks of antecedent event while remaining 2 patients developed between 1 to 3 months.

The common clinical features observed in our study was paraparesis $(63.33 \%$ patients $)$ and quadriparesis in $(36.67 \%$ patients.) Involvement of cranial nerves was observed in $40 \%$, autonomic dysfunction in $33.33 \%$ and respiratory paralysis in $13.33 \%$ patients respectively. In the present study flaccid, ascending, symmetrical weakness with greater involvement of proximal muscles of the lower extremities, was the more prevalent clinical manifestation. Sensory symptoms (paresthesia, tingling sensation) were observed in $63.33 \%$ patients however sensory signs were present only in $6.66 \%$ patients. It was also observed that areflexia was seen in $100 \%$,wasting particularly of distal muscle in $13.33 \%$, sphincter disturbances in $6.67 \%$ of patients respectively.Sundar ${ }^{13}$ in his study of 50 patients of GBS found that most common presentation was motor weakness(48pts) followed by tingling numbness (20pts)and respiratory paralysis(10pts).They also found the most common cranial nerve to be involved was facial nerve.In another study ${ }^{14}$ Lower limb weakness was the most common initial symptom $(51.5 \%)$ like in our study followed by tingling and numbness $(27.3 \%)$. Upper limb onset of disease was found in $6.1 \%$ of cases. $30.3 \%$ of patients had sensory involvement. $39.4 \%$ of patients had cranial nerve involvement and $36.4 \%$ of patients had autonomic involvement at the time of peak disability. $18.2 \%$ of patients required mechanical ventilation.So GBS has varied clinical presentation with motor weakness as the most common one.

The major autonomic manifestations seen in our study was tachycardia (20\%) followed by bradycardia and postural hypotension (6.66\%) each. In various studies, autonomic disturbances were seen in more than $50 \%$ patients. The autonomic disturbance usually manifests as tachycardia but more serious dysfunctions like life threatening arrhythmias, hypotension, hypertension, gatrsointestinal dysmotility are also seen ${ }^{15}$ In the present study $13.33 \%$ patients had respiratory paralysis out of which $75 \%$ patients had bulbar palsy.There was a significant direct correlation seen between presence of bulbar palsy and respiratory failure in our study.Various studies found incidence of respiratory failure 
requiring mechanical ventilation in GBS to be $18.2 \%^{14}$ and $30 \%{ }^{16}$ respectively while another study found that one third of hospitalized GBS patients require mechanical ventilation due to respiratory muscle or oropharyngeal weakness. ${ }^{17}$. Bulbar palsy ${ }^{18}$ and reduction in vital capacity appears to be risk factors or the same. If we can have some indicator for predicting respiratory failure we can be more vigilant and think about elective Intubation.

Nerve conduction velocity is considered as a very useful tool for diagnosis as well as prognostication of AIDP by many authors .In study done by Shubhangi Vithal Dhadke et al ${ }^{1}$ out of 40 patients, 33 patients had mixed sensorimotor demyelinating neuropathy while 7 patients had pure motorneuropathy so all patients had NCV findings suggestive of GBS. In our study pure motor neuropathy was present in majority of patients.

In the present study $83.33 \%$ patients improved at the time of discharge with some residual neurodeficit and $13.33 \%$ patients had severe neurodeficit on discharge while $3.33 \%$ patient died. Neto A et al in her study reported mortality between $2 \%$ and $18 \%{ }^{20}$. Less mortality in our study may be due to early presentation of patient in the hospital and early treatment. Shubhangi Vithal Dhadke et $a 1^{1}$ reported mortality of $20 \%$. Deaths were due to ventilator associated pneumonia, sepsis, and patients reporting very late to hospital for admission.In our study there was not much difference in efficacy with either of the treatment modality, IVIG versus plasmapheresis. Plasmapheresis removes immunoglobulins, complement, and cytokines which plays a role in the pathogenesis of GBS. Cochrane Review, demonstrated the efficacy of PE. It reduced the number of patients requiring mechanical ventilation, shortened the time to extubation, increased the number of patients achieving full strength at 1 year, and reduced the number of patients experiencing severe sequelae at 1 year. These studies also demonstrated that treatment should be started as early as possible (within 7 days is the most effective) but can be done upto 30 days. In 6 patients we started the treatment between 7 and 12 days as they reported late in the hospital but all 6 of them had mild neurological deficit and showed improvement on discharge.

$\mathrm{PE}$ is little expensive, not available everywhere and can be contraindicated in patients with unstable hemodynamics, coagulopathy, sepsis, and problems with vascular access. Intravenous immunoglobulin (IVIg) is the other GBS therapy.A meta-analysis of studies found no difference between IVIg and PE in terms of mortality, improvement at 4 weeks, residual disability, or time on mechanical ventilation. A single study found that IVIg added after PE offered a small, but statistically insignificant, benefit over IVIg alone. The most common IVIg dose is $2 \mathrm{~g} / \mathrm{kg}$ split evenly over 5 days.As treatment with either of the two, PE or IV Ig has not much difference the choice depends upon availability, expertise, cost and contraindications.

\section{Conclusion}

GBS is a illness with varied presentation .We should be aware that among various common antecedent events Dengue fever should not be underestimated specially in India where incidence of Dengue fever is high.In all patients of GBS, HIV testing should be done routinely.We should be vigilant in patients having bulbar palsy as these may develop respiratory paralysis. We found no difference in outcome with either of the two treatment modalities.

\section{References}

1. Dhadke S V, Dhadke N, Bangar S, Korad MB.Clinical Profile of Guillain Barre Syndrome. Journal Of The Association of Physcians Of India. March 2013; 61:168172.

2. Sodalagunta S R, Sodalagunta M B, Sepehrar M, Khorram H, Raja S. GuillainBarré Syndrome: Clinical Profile And Management. GER MED scisep2015; 13: Doc16. 
3. Ropper A H, Brown RH. Adams and Victor`s Principles of neurology. 9th edition New York Mc Graw hill; 2005: 1117-1127.

4. Habib R, Saifudin M D, Islam R,Rahman A. Clinical Profile of Guillain Barre's Syndrome Observations from a Tertiary Care Hospital of Bangladesh. Birdem Medical Journal 2017; 7:1

5. Newswanger D L, Warren C R.GuillainBarréSyndrome.AmFam Physician 2004 May 15; 69(10):2405-2410.

6. Sharma G,SoodS,Sharma S. Seasonal, Age \& Gender Variation of Guillain Barre Syndrome in a Tertiary Referral Center in India. Neuroscience \& Medicine2013; 4: 23-28.

7. Udaya Seneviratne U. Guillain-Barré syndrome .Post graduate medical journal December 2000; 76: 902

8. Chen T Y, Lee C T, Guillain-Barré Syndrome Following Dengue Fever.Annals of emergency medicine july 2007 vol50, Issue 1: 94-95

9. Tanwar V S, Saini A, Sukhija G, Kaur P. Post dengue Guillain Barre syndrome a rare case scenario. International Journal of Advances in Medicine; 2016 Nov; 3(4):1077-1079.

10. Verma R, Sharma P, Garg RK, Atam V, Singh MK, Mehrotra HS. Neurological complications of dengue fever: Experience from a tertiary center of north India. Ann Indian AcadNeurol 2011; 14: 272-8.

11. Booa Y L, Aris MAM, China P W, Wan Aliaa Wan Sulaiman WAW, Basrib H et al. Guillain-Barré syndrome complicating dengue fever. Two case reports. Tzu Chi Medical Journal December 2016; 28, (4): 157-159.

12. Brannagan TH III, Zhou Y. HIVassociated Guillain- Barre syndrome. J Neurol Sci 2003; 208: 39-42.
13. Sundar K, Vasanthan K, Vengadakrishnan K, Satyamurthy P, Sudhakar MK. Clinical Profile of Guillain-Barre Syndrome in a Tertiary Care Center. Int J Sci Stud 2016; 4(9):27-30

14. John J, Kannan A. Clinicalprofile of Guillain Barre Syndrome in a tertiary carecentre. Int J Res Med Sci 2014; 2: 445-7.

15. Ted M, Burns T M .Guillain-Barre' Syndrome Semin Neurol. 2008 April; 28(2):152-167.

16. Paul B S,Bhatia R ,Prasad K,Padma M V.Clinical predictors of mechanical ventilation in guillain Barre syndrome.Neurology India 2012; 6092 :150-153.

17. Meena A. K, Khadilkar S. V, Murthy J. Treatment guidelines for Guillain-Barré Syndrome. Ann Indian Acad Neurol 2011;14,Suppl S1:73-81.

18. Bhargava A, Banakar B F, Pujar G S, Khichar S.A Study of Guillain-Barré Syndrome with reference to cranial neuropathy and its prognostic implications. Journal of neurosciences practice Nov 2014; (1): 543-547.

19. Harms M.Inpatient Management of Guillain-Barré Syndrome. Neurohospitalist . 2011 Apr; 1(2): 78-84.

20. Netto AB, Taly AB, Kulkarni GB, Uma Maheshwara Rao G S, Rao S. Prognosis of patients with Guillain-Barré syndrome requiring mechanical ventilation. Neurol India 2011; 59: 707-11 